\title{
Symposium
}

\section{Choledochal cyst}

\section{Gp Capt Manoj Kumar ${ }^{a, *}$, Brig S. Rajagopalan ${ }^{b}$}

\author{
${ }^{a}$ Associate Professor, Department of Surgery, AFMC, Pune 40, India
}

${ }^{\mathrm{b}}$ Professor \& HOD, Department of Surgery, AFMC, Pune 40, India

\section{Introduction}

Choledochal cyst is a rare congenital dilatation of the bile ducts. The estimated incidence in Western countries varies between 1 in 100,000 and 1 in 150,000. ${ }^{1}$ The incidence is higher in Asia and occurs more in women, with a male to female ratio of $1: 3-4 .^{1,2}$

\section{Classification}

The most widely used subdivision of choledochal cysts is Todani's classification (Fig. 1), which is a modification of the Alonso-Lej classification. ${ }^{3}$ Type I cysts are the most frequently encountered. The intrahepatic part of type IVa and type V cysts occur diffusely or in a part of the liver. Not shown in this figure is type IVb, featuring multiple extrahepatic dilatations, which is a very uncommon condition.

\section{Aetiopathology}

The precise etiology of extrahepatic cysts continues to remain unclear. Choledochal cysts belong to the fibropolycystic disorders and type V (Caroli's disease) and probably the intrahepatic part of type IVa cysts are thought to be ductal plate malformations.

The most commonly accepted theory for choledochal cysts is based on the observation that they are frequently associated with an anomalous pancreatobiliary duct junction (APBDJ) with a common channel more than $15 \mathrm{~mm}$. These are seen in $57 \%-96 \%$ of the cases investigated. The resultant pancreatic juice reflux into the biliary tree causes ductal changes. ${ }^{4-6}$

Abnormal function of the sphincter of Oddi has been reported to predispose to pancreatic reflux into the biliary tree and an association has been seen with increased sphincter of Oddi pressures and spasm. ${ }^{6}$

Inadequate autonomic innervations: Kusunoki et al demonstrated suboptimal number of ganglion cells in the narrow portion if the common bile duct in patients with a choledochal cyst, as compared with controls suggesting a functional obstruction. ${ }^{7,8}$

If choledochal cysts are not resected, a high incidence $(20 \%-30 \%)$ of cholangiocarcinoma has been reported, mainly after the second decade of life, ${ }^{8}$ which formed the basis of resection as state of the art surgical treatment. This policy is further supported by a study that found increasing rate of premalignant changes in resected cysts with advancing age. ${ }^{6}$

\section{Clinical presentation}

The classical triad of jaundice, right upper quadrant mass with abdominal pain is seen in less than $17 \%$ of the cases presenting to any tertiary care centre. ${ }^{6}$ Two-thirds the cases are diagnosed before the age of 10 years and $85 \%$ cases before puberty. Cystic dilatation of the extrahepatic tree can be diagnosed using ultrasound as early as 15 weeks of gestation - a half of these would continue to be asymptomatic in early infancy with the other half presenting with jaundice and a palpable mass. The most important differential diagnosis is biliary atresia.

Rarer presentations include gastric outlet obstruction, neonatal bleeding tendency, duodenal intussusception, and portal hypertension. Older children present with failure to thrive, recurrent cholangitis, and palpable mass in various combinations. Uncommon presentations include spontaneous perforations and portal hypertension.

In $15 \%$ of the patients the presentation is in adulthood and may have features of hepatic changes of cirrhosis, pancreatitis, choledocholithiasis or cholangitis. ${ }^{9-11}$

\footnotetext{
* Corresponding author.

E-mail address: drmanojsurgeon@yahoo.co.in (M. Kumar). 0377-1237/\$ - see front matter ( ) 2012, Armed Forces Medical Services (AFMS). All rights reserved. doi:10.1016/j.mjafi.2012.04.011
} 


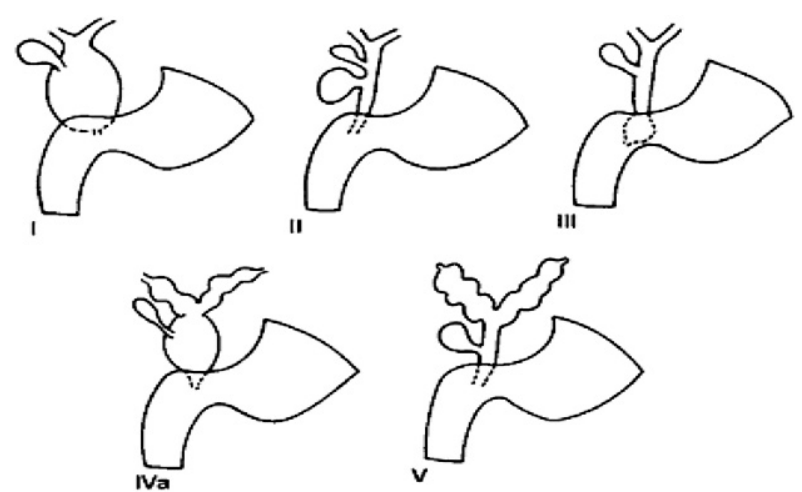

Fig. 1 - Classification of choledochal cysts (Todani). Type I: Cystic or fusiform dilatation of hepatic and common bile duct $(40 \%-85 \%)$. Type II: Diverticulum of the common bile duct (2\%-3\%). Type III: Choledochocele:Intraduodenal CBD dilatation (1.4\%-5.6\%). Type IVa: Intra- and extrahepatic bile duct dilatation (18\%-20\%). Type V: Intrathepatic bile duct dilatation.

\section{Investigations}

Ultrasound imaging of the heptobiliary tree has a specificity of almost $97 \%$ in children and is therefore the first line of investigation. Presence of a distended gall bladder helps differentiate biliary atresia. However it has limitations in imaging a choledochocele. ${ }^{12}$

Magnetic Resonance Cholangiopancreaticogram (MRCP) is the investigation of choice and represents the "gold standard" today. MRCP helps in clearly outline the proximal extent of resection and distally pancreaticobiliary malunion. The imaging of common channel and distal pancreatic duct may however be suboptimal. ${ }^{13}$

Heptobiliary scintigraphy is rarely used as an initial investigation to diagnose or plan the extent of resection. The characteristic image is one of delayed filling of the bile duct cysts followed by persistent radioisotope retention. This modality is more useful for assessing a high biliary-enteric anastomosis postoperatively.

ERCP in adult patients preoperatively can be used in patients with severe cholangitis and for extraction of calculi in the distal bile duct.

\section{Management options}

\section{Timing of definitive surgery}

(a) Antenatally diagnosed patients should be offered definitive surgery postnatal in the first two months of life for best results if they are symptomatic with features of cholangitis or jaundice. For asymptomatic patients with no jaundice and preserved liver function, early definitive surgery should be carried out by the sixth month.

(b) Older children and adults should be offered definitive resection as and when they are diagnosed. This avoids possible complications of cholangitis, pancreatitis, spontaneous perforations, hepaticolithiasis and cholangitic abscesses and the ensuing mortality and technically difficult surgery.

(c) Following severe cholangitis the definitive surgery should be delayed for 6-12 weeks.

(d) Following internal drainage procedures, $70 \%$ patients require reoperation for occurrence cholangitis and hepatolithiasis. Even in the asymptomatic group patients should be offered early definitive cyst resection and reconstruction as prophylaxis against malignancy. ${ }^{14,15}$

\section{Radical cyst excision and hepaticojejunostomy}

The aim of definitive surgery for choledochal cyst includes:

(a) Excision of the cyst wall and the gall bladder - reducing risk of malignancy.

(b) Interruption of pancreatic-biliary reflux.

(c) Reconstruction of the biliary-enteric channel for optimal drainage of bile.

The salient features include defining the extent of resection preoperatively and dissecting in the plane between the cysts, hepatic artery medially and portal vein posteriorly. Cyst is transected proximally till there is change in the nature and caliber of the hepatic ducts. Distally the dissection enters the intrapancreatic tapering part of the cyst of approximate $3 \mathrm{~mm}$ diameter. A wide $2 \mathrm{~cm}$ end-to-side anastomosis is made between the hepatic duct and a $40 \mathrm{~cm}$ retrocolic Roux-en-Y loop of jejunum.

Type IV choledochal cysts with localized intrahepatic involvement can be offered relevant partial hepatectomy. ${ }^{16,17}$ Bilateral involvements with evidence of biliary cirrhosis have liver transplantation as the only solution. Drainage of the extrahepatic component alone in the presence of intrahepatic duct cysts has a high incidence of malignancy.

Type III choledochoceles are traditionally treated with internal drainage into the duodenum due to the lower risk of malignancy and the enormous attraction of the endoscopic sphincterotomy. ${ }^{6}$

The surgical options available in the event of a difficult cyst following recurrent cholangitis, pancreatitis or spontaneous cyst perforation-peritonitis, where the planes of surgical dissection will be obscured, are:

(a) Lillys technique - where the medial and posterior walls are dissected in the submucosal plane from the hepatic artery and portal vein respectively.

(b) Internal drainage of the cyst to the duodenum or jejunum with plan to resect the cyst after 6-12 weeks.

(c) Hepp procedure - Partial cyst excision and choledochocysto-jejunostomy.

All of these have a significant residual risk of malignancy from the remnant part of the duct which after a radical cyst excision and reconstruction is $0.7 \%$ only. ${ }^{18}$

Postoperatively patients undergo annual hepatobiliary ultrasound and liver function tests. Late complications include anastomotic strictures, intrahepatic calculi and cholangiocarcinomas in the distal part of the choledochus. The incidence of anastomotic stricture can be reduced by a wider 
and higher (hepaticojejunostomy instead of choledochojejunostomy) anastomosis.

\section{Conclusion}

Choledochal cysts, though relatively uncommon, can have protean presentations. Key points to be imbibed are: high index of suspicion for diagnosis; hepatobiliary ultrasound and MRCP are the present day standards for imaging; early surgery should be the norm to avoid possible late complications of cholangitis, cirrhosis, hepaticolithiasis and spontaneous perforation; radical excision of the cyst with a wide and high hepaticojejunostomy is the best approach; choledochoceles can be managed by internal drainage; well-timed surgery in a tertiary care settings have the best prognosis and there remains a low risk of cholangiocarcinoma even after complete radical resection.

\section{Conflicts of interest}

None identified.

\section{RE F E R E N C E S}

1. Lu S. Biliary cysts and strictures. In: Kaplowitz N, ed. Liver and Biliary Diseases. Baltimore, MD: Williams and Wilkins; 1996: 739-753.

2. Lipsett P. Biliary atresia and cysts. In: Pitt $\mathrm{H}$, ed. The Biliary Tract (Part of Clinical Gastroenterology), vol. 11. London, UK: Balliere Kindall; 1997:626-641. 4.

3. Todani T, Watanabe $\mathrm{Y}$, Narusue $\mathrm{M}$, et al. Congenital bile duct cysts, classification, operative procedures, and review of thirty-seven cases including cancer arising from choledochal cyst. Am J Surg. 1977;134:263-269.
4. Babbitt DP. Congenital choledochal cysts: new etiological concepts on anomalous relationships of the common bile duct and pancreatic bulb. Ann Radiol. 1969;12:231-240.

5. Zhao L, Li Z, Ma H, et al. Congenital choledochal cyst with pancreatitis. Chin Med J (Engl). 1999;112:637-640.

6. Metcalfe MS, Wemyss-Holden SA, Maddern GJ. Management dilemmas with choledochal cyst. Arch Surg. 2003;138:333-339.

7. Kusunoki M, Saitoh N, Yamamura T, Fujita S, Takahashi T, Utsunomiya J. Choledochal cysts: oligoganglionosis in the narrow portion of the choledochus. Arch Surg. 1988;123:984-986.

8. Shimotake T, Iwai N, Yanagihara J, Inoue K, Fushiki S. Innervation patterns in congenital biliary dilatation. Eur $\mathrm{J}$ Pediatr Surg. 1995;5:265-270.

9. Seema Sharma A, Seth A, Taluja V, Bagga D, Aneja S. Spontaneous rupture of choledochal cyst. Indian J Pediatr. 2000;67:155-156.

10. Lin SL, Shan KM, Hung YB, Ng SH, Lin CY. Choledochal cyst associated with acute acalculous cholecystitis. J Pediatr Gastroenterol Nutr. 2000;31:307-308.

11. Ando K, Miyano T, Kohno S, Takamizawa S, Lane G. Spontaneous perforation of choledochal cyst: a study of 13 cases. Eur J Pediatr Surg. 1998;8:23-25.

12. Lee HC, Yeung CY, Chang PY, Sheu JC, Wang NL. Dilatation of the biliary tree in children: sonographic diagnosis and its clinical significance. J Ultrasound Med. 2000;19:177-184.

13. Govil S, Justus A, Korah I, Perakath A, Zachariah N, Sen S. Choledochal cysts: evaluation with MR cholangiography. Abdom Imaging. 1998;23:616-619.

14. Chijiiwa K, Koga A. Surgical management and long-term follow-up of patients with choledochal cysts. Am J Surg. 1993;165:238-242.

15. Chaudhary A, Dhar P, Sachdev A. Reoperative surgery for choledochal cysts. Br J Surg. 1997;84:781-784.

16. Liu CL, Fan ST, Lo CM, Lam CM, Poon RT, Wong J. Choledochal cysts in adults. Arch Surg. 2002;137:465-468.

17. Nakayama $H$, Masuda H, Ugajin W, Koshinaga T, Fukuzawa M. Left hepatic lobectomy for type IV-A choledochal cyst. Am J Surg. 2000;66:1020-1022.

18. Watanabe Y, Toki A, Todani T. Bile duct cancer developed after cyst excision for choledochal cyst. J Hepatobiliary Pancreat Surg. 1999;6:207-212. 